\title{
The dynamic relationship between cognitive function and walking speed: the English Longitudinal Study of Ageing
}

\author{
Catharine R Gale • Michael Allerhand • \\ Avan Aihie Sayer • Cyrus Cooper • Ian J Deary
}

Received: 31 October 2013 / Accepted: 26 June 2014 / Published online: 5 July 2014

(C) The Author(s) 2014. This article is published with open access at Springerlink.com

\begin{abstract}
Cross-sectional studies show that older people with better cognition tend to walk faster. Whether this association reflects an influence of fluid cognition upon walking speed, vice versa, a bidirectional relationship or the effect of common causes is unclear. We used linear mixed effects models to examine the dynamic relationship between usual walking speed and fluid cognition, as measured by executive function, verbal memory and processing speed, in 2,654 men and women aged 60 to over 90 years from the English Longitudinal Study of Ageing. There was a bidirectional relationship between walking speed and fluid cognition. After adjusting for age and sex, better performance on executive function, memory and processing speed was associated with less yearly decline in walking speed over the 6-year follow-up period; faster walking speed was associated with less yearly decline in each cognitive domain; and less yearly decline in each cognitive domain was associated with less yearly decline in walking speed. Effect sizes were small. After further adjustment for other covariates, effect sizes were attenuated but
\end{abstract}

C. R. Gale $\cdot$ M. Allerhand $\cdot$ I. J. Deary

Centre for Cognitive Ageing and Cognitive Epidemiology,

Department of Psychology, University of Edinburgh,

Edinburgh, UK

C. R. Gale · A. A. Sayer C C. Cooper

MRC Lifecourse Epidemiology Unit, University of

Southampton, Southampton, UK

C. R. Gale $(\bowtie)$

MRC Lifecourse Epidemiology Unit, Southampton General Hospital, Southampton SO16 6YD, UK

e-mail: crg@mrc.soton.ac.uk most remained statistically significant. We found some evidence that walking speed and the fluid cognitive domains of executive function and processing speed may change in parallel with increasing age. Investigation of the association between walking speed and cognition earlier in life is needed to better understand the origins of this relation and inform the development and timing of interventions.

Keywords Cohort studies - Cognitive function . Walking speed · Ageing

\section{Introduction}

Maintaining cognitive and motor capabilities with increasing age is crucial for living independently, carrying out everyday activities and quality of life. There is considerable inter-individual variation in how these capabilities change with age. While some domains of cognitive function, such as verbal ability and general knowledge, show little change with advancing age, in general, fluid cognitive abilities, such as reasoning, executive function, processing speed and memory decline from midlife or even earlier (Park and Reuter-Lorenz 2009; Singh-Manoux et al. 2012). Gait is a complex motor function that tends to deteriorate in later life, although it is unclear how early in the life course these changes start. Usual walking speed is the aspect of gait that is most commonly assessed. Most longitudinal data on walking speed are based on people aged 60 or more, but comparisons of different age groups suggest that, 
like cognition, walking speed too may start declining before midlife (Bohannon 1997; Cooper et al. 2011; Himann et al. 1988). Poorer performance on tests of fluid cognitive abilities, slower usual walking speed or faster decline in either cognitive or motor capability are all associated with increased mortality in older people (Backman and MacDonald 2006; Studenski et al. 2011; White et al. 2013).

Evidence from cross-sectional analyses shows that there is a low to moderate correlation between scores on tests of fluid cognitive ability and walking speed, such that older people with better cognition tend to walk faster (Holtzer et al. 2006; Killane et al. 2013; Martin et al. 2013; Rosano et al. 2005; Soumare et al. 2009; Watson et al. 2010). These findings seem to apply particularly to performance on tests of executive function, processing speed or attention - thought to be of particular importance for planning and execution of movements (Yogev-Seligmann et al. 2008). Establishing whether these associations reflect an influence of fluid cognition upon walking speed, vice versa, or a bidirectional relationship and whether common causal factors underlie any such link requires longitudinal studies of older people. Few such studies have examined these issues, as highlighted in a recent review (Clouston et al. 2013). Results of prospective investigations of the relation between performance on different domains of fluid cognition and decline in walking speed have produced inconsistent findings (Soumare et al. 2009; Tabbarah et al. 2002; Watson et al. 2010), and while one study has demonstrated that slower usual walking speed is predictive of decline in attention and psychomotor speed (Inzitari et al. 2007), it is unclear whether slower walking speed is associated with change in other domains of fluid cognition. It is also uncertain whether changes in different domains of fluid cognition are associated with change in walking speed, although, in one cohort, less decline on a total cognitive score based in part on assessment of fluid cognitive abilities was associated with less decline in walking speed over a 7year period (Tabbarah et al. 2002). In all these studies where a significant association remained after multivariate adjustment, effect sizes were small. Studies varied in the range of potential confounding variables included in the models, so the extent to which these factors account for the association remains unclear. Understanding the nature of the relationship between walking speed and different domains of fluid cognition in older people could help to inform the development of interventions to prevent or ameliorate mobility limitations and slow cognitive decline.

The English Longitudinal Study of Ageing (ELSA) is a large population-based sample of older men and women. We used these data to examine the dynamic relationship between fluid cognition, as measured by tests of executive function, verbal memory and processing speed, and usual walking speed over an average period of 6 years in people aged 60 to over 90 years.

\section{Methods}

\section{Participants}

The data for this study come from the ELSA. The sample for ELSA was based on people aged $\geq 50$ years who had participated in the Health Survey for England in 1998, 1999 or 2001 (Steptoe et al. 2013). It was drawn by postcode sector, stratified by health authority and proportion of households in non-manual socioeconomic groups. In 2002-2003, 11,392 people participated in wave 1. Subsequent follow-up surveys have taken place approximately every 2 years. Ethical approval was obtained from the Multicentre Research and Ethics Committee. Participants gave written informed consent.

\section{Measures}

\section{Cognitive function}

The ELSA data include scores on four tests of cognitive function taken at each follow-up occasion: verbal fluency, immediate and delayed verbal memory, and attention. Verbal (semantic) fluency was assessed by asking participants to name as many animals as they could think of in $1 \mathrm{~min}$. Immediate and delayed verbal memory was assessed by presenting a list of 10 nouns aurally on a computer, one every $2 \mathrm{~s}$. Participants were asked to recall as many words as possible immediately and again after a short delay during which they carried out the other cognitive tests. Attention and mental speed were assessed using a letter cancellation task. Participants were given a clipboard to which was attached a page of 780 random letters of the alphabet set out in a grid of 26 rows and 30 columns and were asked to cross out as many target letters ( $\mathrm{P}$ and $\mathrm{W}$ ) as possible in $1 \mathrm{~min}$. An example was given at the top of the page to show participants how to cross out the letters. Participants 
were asked to work across and down the page as if they were reading and to perform the task as quickly and accurately as possible. Scores on these tests were used as measures of three domains of cognitive function: the score on the animal naming task was taken as a measure of executive function, the sum of the scores on the immediate and delayed recall tasks were taken as a measure of memory (these scores were highly correlated: $r=0.70$ at wave 1 ), and the score for number of target letters correctly identified on the letter cancellation task was taken as a measure of processing speed/attention (termed processing speed hereafter). Each variable was centred on the variable's mean at wave 1 and scaled into units of its standard deviation at wave 1 .

\section{Walking speed}

Walking speed was assessed in participants aged 60 and over by measuring the time taken to walk a distance of $8 \mathrm{ft}$ at usual pace. Before participants performed the test, the interviewer assessed whether they could do so safely. Use of walking aids such as a stick or Zimmer frame were permitted in the test; approximately $4 \%$ of those who completed the test used these aids. Participants who had to rely on the support of another person or who were assessed as being in danger of falling were not asked to take the test. The timed walk was repeated and the mean of the two measurements was calculated.

\section{Covariates}

A priori, we identified potential confounding factors; that is factors previously shown to be associated with both cognitive function and walking speed in later life. These factors were socioeconomic status, educational attainment, height, adiposity, muscle strength, smoking, physical activity, chronic physical illness, blood pressure and depressive symptoms (Atkinson et al. 2005; Christensen et al. 1997; Deary et al. 2011; Demakakos et al. 2013; Dore et al. 2008; Elias et al. 1993; Guven and Lee 2013; Hardy et al. 2013; Kenny et al. 2013; Koster et al. 2005; Kramer et al. 2006; Nooyens et al. 2008; Rosano et al. 2011; Waldstein et al. 2001; Zaninotto et al. 2013).

Socioeconomic status was indexed by total household wealth, including savings and investments, value of any property or business assets, net of debt, excluding pension assets at wave 1 . Household wealth has been identified as the most accurate indicator of long-term socioeconomic circumstances in ELSA (Banks et al. 2003). Educational attainment was defined by age at leaving full-time education. This was coded as a continuous linear scale 1 to 7 (see Table 1). Participants provided information about their smoking habits and responded to three questions about the frequency with which they did vigorous, moderate or mild exercise. We ranked the combinations of responses to these questions according to the amount and intensity of exercise involved to provide an estimate of usual physical activity. Symptoms of depression were assessed using the eightitem version of the Center for Epidemiologic Studies Depression Scale (CES-D) (Steffick and The HRS working group 2000). Participants were asked whether a doctor had ever told them that they had any of the following conditions: angina, heart attack, congestive heart failure, diabetes or high blood sugar, a stroke, chronic lung disease, arthritis or rheumatism, or cancer. For the purposes of these analyses, we created a single variable to indicate history of heart disease from the variables on angina, heart attack and congestive heart failure.

At wave 2 in 2004-2005, participants who completed the main interview were invited to have a visit from a nurse that included anthropometric measurements and measurement of blood pressure and grip strength. Height and weight were measured with a portable stadiometer and electronic scales, respectively. Body mass index (BMI) was calculated as weight (in kilograms)/height (in metres) ${ }^{2}$. Blood pressure was measured three times on the right arm; mean systolic and diastolic blood pressure was calculated based on the second and third measurements only. Maximum handgrip strength was measured three times on each side using a dynamometer; the best of these measurements was used for analysis.

\section{Analytical sample}

Of the 6,974 study members aged 60 to over 90 years who completed the interviews in person at wave 1 , $3,708(53 \%)$ were interviewed at wave 4 in 2008 2009. We excluded cases who had reported by wave 1 that a doctor had told them that they had Alzheimer's disease, Parkinson's disease, dementia, organic brain syndrome or serious memory impairment $(N=120)$. In the present analysis, we excluded cases with a monotonic pattern of missing values in any of the four timevarying outcomes. The sample then consisted of 2,654 
Table 1 Characteristics of the study participants at baseline (wave 1) $(n=2,654)$

\begin{tabular}{|c|c|}
\hline Characteristic & Mean (SD) or no. $(\%)$ \\
\hline Age (year) & $68.79(6.33)$ \\
\hline Female & $1,476(55.6)$ \\
\hline \multicolumn{2}{|l|}{ Age finished full-time education } \\
\hline Did not attend school & $12(0.5)$ \\
\hline$\leq 14$ & $686(26.4)$ \\
\hline 15 & $818(31.5)$ \\
\hline 16 & $471(18.1)$ \\
\hline 17 & $193(7.4)$ \\
\hline 18 & $115(4.4)$ \\
\hline$\geq 19$ & $305(11.7)$ \\
\hline \multicolumn{2}{|l|}{ Household wealth (quintiles) } \\
\hline 1 & $379(14.4)$ \\
\hline 2 & $487(18.5)$ \\
\hline 3 & $550(20.8)$ \\
\hline 4 & $577(21.9)$ \\
\hline 5 & $645(24.5)$ \\
\hline Heart disease & $342(12.9)$ \\
\hline Stroke & $93(3.5)$ \\
\hline Diabetes & $163(6.1)$ \\
\hline Chronic lung disease & $156(5.9)$ \\
\hline Asthma & $297(11.2)$ \\
\hline Arthritis & $895(33.7)$ \\
\hline Osteoporosis & $150(5.7)$ \\
\hline Cancer & $173(6.5)$ \\
\hline Depressive symptom score & $0.7(0.54)$ \\
\hline \multicolumn{2}{|l|}{ Smoking } \\
\hline Never & $1004(37.8)$ \\
\hline Ex- & $1319(49.7)$ \\
\hline Current & $331(12.5)$ \\
\hline \multicolumn{2}{|l|}{ Exercise } \\
\hline Low & $730(27.5)$ \\
\hline 2 & $880(33.2)$ \\
\hline 3 & $561(21.1)$ \\
\hline High & $483(18.2)$ \\
\hline *Grip strength (kg) & $30.2(10.3)$ \\
\hline *Height $(\mathrm{cm})$ & $164.7(9.3)$ \\
\hline *Waist-hip ratio & $0.9(0.08)$ \\
\hline${ }^{*}$ BMI $\left(\mathrm{kg} / \mathrm{m}^{2}\right)$ & $27.7(4.49)$ \\
\hline *Systolic blood pressure (mmHg) & $138.1(19.0)$ \\
\hline *Diastolic blood pressure (mmHg) & $74.3(10.8)$ \\
\hline
\end{tabular}

*Data available at wave 2

The covariates were complete except for the following numbers of missing values: education 54 , wealth 16 , grip strength 303 , height 338, waist-hip ratio 338, BMI 361, systolic and diastolic BP 542 people who had complete data at waves 1 and 4 . No attempt was made to impute missing values. Instead, we carried out a sensitivity analysis in order to show the missingness was ignorable under maximum likelihood estimation. The sensitivity analysis derived bootstrapped confidence intervals around the parameters estimates of each model to explore the variation in parameters that could result if missing values were not missing but imputed to the limits of plausibility. In a two-stage procedure, we first estimated prediction intervals for each missing value using individual growth curves based on all available information from shrinkage estimates of each person's growth parameters. In the second stage, we created 50 data sets each with different imputed missing values by randomly sampling with uniform probability within the prediction intervals. The models were fitted to each of these data sets and the variation in the resulting parameters was assessed. The parameters estimated with missing values ignored were all within the bootstrapped confidence intervals, and the intervals indicated that the sign and significance of model parameters across the multiple imputed data sets was the same as was obtained with missing values ignored. Therefore, we judged the occurrence of monotone missingness to be ignorable.

\section{Statistical methods}

We used linear mixed effects models of the relationship between the rate of change of cognition and the rate of change of walking speed, and vice versa, in our fourwave longitudinal data. Models were fitted using the "Imer" function of R (version 3.0.0). We did not directly use time-varying predictors, but instead derived timeinvariant predictors representing linear slope, as has been done previously (Atkinson et al. 2010). These were derived as the change per year in walking speed, and in each domain of fluid cognition, by subtracting the relevant scores at wave 4 from scores at wave 1 and dividing the difference by the time in years between the two testing occasions. To test the assumption of linearity, we fitted models of each of our outcome variables regressed on age and age squared for each person. We found the curvature term was significant $(p<0.05)$ in less than $4.5 \%$ of cases, and therefore judged linear slopes to be acceptable. Initial models were adjusted for age, age-squared and sex; these entered the models as main effects since there were no significant interactions. In model 2, we further adjusted for educational 
attainment and household wealth. In model 3, we further adjusted for all remaining covariates: doctor diagnoses of heart disease, stroke, diabetes, hypertension, osteoporosis, arthritis or rheumatism, chronic lung disease, asthma or cancer, physical activity, smoking, depressive symptoms, BMI, waist-to-hip ratio, blood pressure and grip strength. All these covariates were treated as timeinvariant.

\section{Results}

Baseline demographic and health-related characteristics of the 2,654 men and women in the study sample are shown in Table 1.

Table 2 shows the Pearson correlations between the various measures of walking speed and cognition (at baseline, at follow-up and the change between those time points), together with mean (SD) values for each variable. At baseline and at follow-up, performance on each domain of cognition assessed-executive function, memory and processing speed - tended to be better in those with faster walking speed. On average, mean walking speed and mean scores for each domain of cognitive function assessed fell over the follow-up period. Change in walking speed was positively correlated with change in each domain of cognition assessed and the size of each of these correlation coefficients was almost identical ( $r$ ranged from 0.061 to 0.065 ), indicating that people with less decline in each domain of cognitive function since baseline tended to experience less slowing in walking speed. As expected, change in one domain of cognitive function was correlated with change in the other two domains, but the size of these correlation coefficients differed little from those observed with change in walking speed.

Table 3 shows the results of mixed effects models of the relationship between a SD increment in scores on each domain of cognition at baseline and yearly change in walking speed between baseline and follow-up. In models adjusting for age and sex only, better performance in each domain of cognition at baseline was associated with less yearly decline in walking speed. The effect size was small: for a SD increment in executive function, memory or processing speed, the yearly decline in walking speed was smaller by $0.061,0.047$ or 0.036 of a SD. Further adjustment for education and household wealth attenuated effect sizes but they remained statistically significant. Further adjustment for the remaining covariates (anthropometric and health-related variables) weakened all associations still further such that the associations between baseline memory or processing speed and change in walking speed ceased to be significant. The relationship between baseline executive function and change in walking speed remained statistically significant.

Table 4 shows results of models of baseline walking speed in relation to yearly change in performance on each domain of cognition by the end of follow-up. In models adjusting for age and sex only, faster walking speed was associated with significantly less yearly decline in each domain of cognition: a SD increment in walking speed was associated with $0.076,0.065$ and $0.050 \mathrm{SD}$ less yearly decline in executive function, memory and processing speed, respectively. Further adjustment first for education and household wealth and then in addition for anthropometric and healthrelated variables attenuated effects but all associations remained statistically significant.

Table 5 shows results of equivalent models of the relationship between yearly change in each domain of cognition and yearly change in walking speed over the follow-up period. Less yearly decline in each domain of cognition was associated with less yearly decline in walking speed. In models adjusting for age and sex, a SD less yearly decline in executive function, memory or processing speed was associated with $0.058,0.046$ and 0.047 SD less yearly decline in walking speed, respectively. Further adjustment for education and household wealth had small attenuating effects and all associations remained statistically significant. After additional adjustment for the anthropometric and health-related variables, the association between yearly decline in memory and yearly decline in walking speed was no longer significant, but the associations between yearly decline in executive function or processing speed and yearly decline in walking speed remained significant.

\section{Discussion}

In this prospective study of 2,654 men and women aged 60 to over 90 years, there was a bidirectional relationship between walking speed and fluid cognition. After adjusting for age and sex, people with better baseline performance on tests of executive function, memory and processing speed experienced less yearly decline in walking speed over the average 6-year follow-up period; 


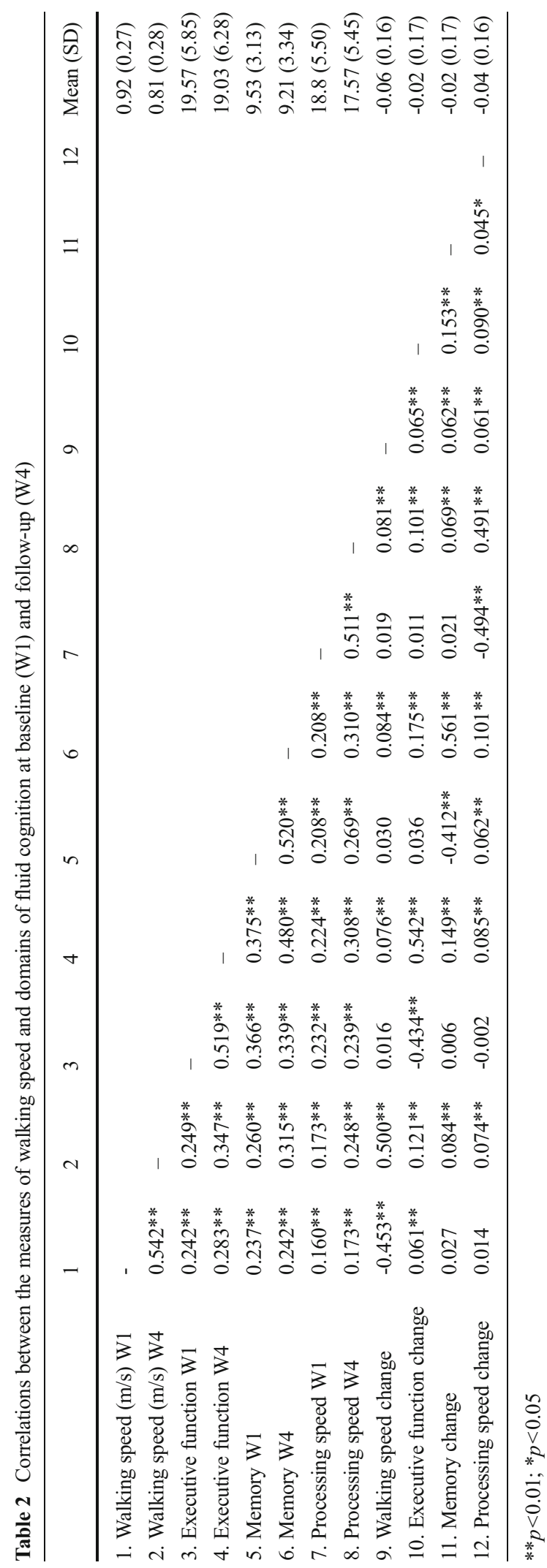

similarly, people who walked faster at baseline experienced less yearly decline on each cognitive domain. Extent of yearly change in each cognitive domain over the follow-up period was associated with extent of yearly change in walking speed. Effect sizes were small, ranging from 0.04 to 0.06 of a SD. After further adjustment for education, household wealth, anthropometric and health-related factors, associations were weakened but most remained statistically significant.

\section{Comparison with previous studies}

Most of the few previous studies into the longitudinal associations between fluid cognitive abilities and walking speed in older people have focussed on cognition as a predictor of decline in walking speed (Clouston et al. 2013). They found that greater decline in walking speed was associated with poorer baseline performance on some, if not all, domains of fluid cognition (Soumare et al. 2009; Watson et al. 2010) or with decline in cognition, based on a combined score on tests of several domains (Tabbarah et al. 2002). Greater decline in walking speed has also been linked with poorer baseline performance or greater change in score on the Modified Mini-Mental State Examination (Atkinson et al. 2010). In our study, as in those described above (Soumare et al. 2009; Watson et al. 2010), the difference in effect size between those domains of fluid cognition that were significantly associated with decline in walking speed and those that were not was very small. Evidence from a small pilot randomized controlled trial of cognitive training, focussed primarily on executive function and attention but also visuospatial skills and processing speed, suggests that improving performance in these domains of cognition may lead to increases in walking speed in older people (Verghese et al. 2010). Whether the beneficial effect seen during this trial was due to improvements in a specific cognitive domain or in the multiple domains targeted remains unclear.

There have been few previous investigations into whether walking speed in linked with change in particular domains of fluid cognition (Clouston et al. 2013), and evidence that it is predictive of change in score on the Mini Mental State Examination have been inconsistent (Alfaro-Acha et al. 2007; Atkinson et al. 2010; Auyeung et al. 2011; Deshpande et al. 2009). In the Health, Aging and Body Composition Study, participants with slower walking speed experienced a significant decline in attention and psychomotor speed, as 
Table 3 Relationship between scores on different domains of cognition at baseline and change in walking speed over the follow-up period

\begin{tabular}{lllll}
\hline Predictor & Model $^{\mathrm{a}}$ & \multicolumn{2}{l}{$\begin{array}{l}\text { Regression coefficient for } \\
\text { change in walking speed }\end{array}$} \\
\cline { 3 - 6 } & \multicolumn{5}{c}{ Coefficient } & SE & $p$ value \\
\hline Cognition at baseline, per SD increment & & \\
Executive function & 1 & 0.061 & 0.010 & $<0.01$ \\
Memory & 1 & 0.047 & 0.010 & $<0.01$ \\
Processing speed & 1 & 0.036 & 0.010 & $<0.01$ \\
Executive function & 2 & 0.032 & 0.010 & $<0.01$ \\
Memory & 2 & 0.020 & 0.010 & $<0.01$ \\
Processing speed & 2 & 0.025 & 0.011 & $<0.01$ \\
Executive function & 3 & 0.025 & 0.011 & 0.023 \\
Memory & 3 & 0.018 & 0.012 & 0.115 \\
Processing speed & 3 & 0.017 & 0.011 & 0.123 \\
\hline
\end{tabular}

${ }^{\text {a }}$ Models: 1 - adjusted for age, age-squared and sex; 2-further adjusted for education, and household wealth at baseline; 3 - further adjusted for self-reported doctor diagnoses of heart disease, stroke, diabetes, hypertension, osteoporosis, arthritis or rheumatism, chronic lung disease, asthma or cancer, physical activity, smoking, and depressive symptoms at baseline, plus BMI, waistto-hip ratio, grip strength and blood pressure at wave 2

measured by performance on the Digit Symbol Substitution test (Inzitari et al. 2007). Our findings suggest that slower walking speed may also be a risk factor for declines in other domains of fluid cognition. However, it is worth noting that walking speed is just one of many measurable facets of gait. There is some evidence that facets of gait may differ in the strength with which they are linked to specific domains of cognition. In a longitudinal study which used factor analysis of eight different gait measures in non-demented older people, the resulting 'pace' and 'rhythm' and 'variability' factors were not equally predictive of cognitive decline in different domains; worse performance on the 'pace' factor-on which walking speed and stride length loaded highly - was associated specifically with decline in executive function, while worse performance on 'rhythm'-primarily a reflection of cadence, swing time and stance time-was associated specifically with decline in memory (Verghese et al. 2007).

\section{Potential mechanisms}

The associations we observed in this study were attenuated after adjustment for covariates, including education, household wealth, anthropometric and healthrelated factors, but most associations persisted. It may be that brain small vessel disease is a common aetiology underlying these bi-directional associations. There is considerable evidence of the role that white matter damage and brain atrophy play in age-related cognitive decline (Debette and Markus 2010; Jokinen et al. 2012; Schmidt et al. 2007). Cross-sectional observations

Table 4 Relationship between walking speed at baseline and change in different domains of cognition over the follow-up period

\begin{tabular}{|c|c|c|c|c|c|}
\hline \multirow[t]{2}{*}{ Predictor } & \multirow[t]{2}{*}{ Model $^{\mathrm{a}}$} & \multicolumn{4}{|c|}{ Regression coefficient for change in cognition } \\
\hline & & Cognitive domain & Coefficient & SE & $p$ value \\
\hline \multirow{9}{*}{$\begin{array}{l}\text { Walking speed at baseline, } \\
\text { per SD increment }\end{array}$} & 1 & Executive function & 0.076 & 0.010 & $<0.01$ \\
\hline & 1 & Memory & 0.065 & 0.011 & $<0.01$ \\
\hline & 1 & Processing speed & 0.050 & 0.009 & $<0.01$ \\
\hline & 2 & Executive function & 0.045 & 0.011 & $<0.01$ \\
\hline & 2 & Memory & 0.041 & 0.011 & $<0.01$ \\
\hline & 2 & Processing speed & 0.037 & 0.010 & $<0.01$ \\
\hline & 3 & Executive function & 0.036 & 0.013 & $<0.01$ \\
\hline & 3 & Memory & 0.031 & 0.013 & 0.015 \\
\hline & 3 & Processing speed & 0.025 & 0.012 & 0.038 \\
\hline
\end{tabular}

\footnotetext{
${ }^{\text {a }}$ Models: 1—adjusted for age, age-squared and sex; 2-further adjusted for education, and household wealth at baseline; 3-further adjusted for self-reported doctor diagnoses of heart disease, stroke, diabetes, hypertension, osteoporosis, arthritis or rheumatism, chronic lung disease, asthma or cancer, physical activity, smoking, and depressive symptoms at baseline, plus BMI, waist-to-hip ratio, grip strength and blood pressure at wave 2
} 
Table 5 Relationship between change in different domains of cognition and change in walking speed over the follow-up period

\begin{tabular}{lllll}
\hline Predictor & Model $^{\mathrm{a}}$ & \multicolumn{2}{l}{$\begin{array}{l}\text { Regression coefficient for } \\
\text { change in walking speed }\end{array}$} \\
\cline { 3 - 5 } & \multicolumn{5}{c}{ Coefficient } & SE & $p$ value \\
\hline Change in cognition, per SD increment & & \\
Executive function & 1 & 0.058 & 0.011 & $<0.01$ \\
Memory & 1 & 0.046 & 0.011 & $<0.01$ \\
Processing speed & 1 & 0.047 & 0.011 & $<0.01$ \\
Executive function & 2 & 0.036 & 0.011 & $<0.01$ \\
Memory & 2 & 0.023 & 0.011 & 0.040 \\
Processing speed & 2 & 0.029 & 0.011 & 0.011 \\
Executive function & 3 & 0.036 & 0.012 & $<0.01$ \\
Memory & 3 & 0.011 & 0.012 & 0.378 \\
Processing speed & 3 & 0.025 & 0.012 & 0.041 \\
\hline
\end{tabular}

${ }^{\text {a }}$ Models: 1-adjusted for age, age-squared and sex; 2-further adjusted for education, and household wealth at baseline; 3-further adjusted for self-reported doctor diagnoses of heart disease, stroke, diabetes, hypertension, osteoporosis, arthritis or rheumatism, chronic lung disease, asthma or cancer, physical activity, smoking, and depressive symptoms at baseline, plus BMI, waistto-hip ratio, grip strength and blood pressure at wave 2

in the Cardiovascular Health Study have shown that slower walking speed is linked with a higher prevalence of white matter disease and subclinical strokes in older people who were free from dementia (Rosano et al. 2006), and a recent longitudinal investigation from the Tasmanian Study of Cognition and Gait demonstrated that structural changes in the brain, such as white matter and hippocampal atrophy and increasing white matter lesions, were associated with decline in walking speed in older people (Callisaya et al. 2013). Another possibility may be that some common biological process of cellular senescence underlies the bidirectional association between cognition and walking speed (Campisi and d'Adda di Fagagna 2007). Cellular senescence is an established cellular stress response to prevent proliferation of cells exposed to potentially oncogenic stimuli. Senescent cells occur with increasing frequency in older tissues and it has been hypothesized that the secretion of numerous pro-inflammatory cytokines, growth factors and proteases that accompanies cellular senescence may be implicated in a variety of age-related pathologies, including decline in cognitive and motor function (Campisi et al. 2011).
Strengths and limitations

The strengths of our study include the large sample size, the fact that it is representative of the communitydwelling English population aged 60 and over (Taylor et al. 2003), and the availability of information on a range of potential confounding. There are also some weaknesses. Firstly, a small proportion of people (around $8 \%$ at wave 1) did not do the walking speed test because they were unable to walk alone or had health restrictions. This may mean that our results under-estimate the strength of association between cognition and walking speed. Secondly, we had no data on other facets of gait and walking speed was assessed under only one condition - usual pace - so we were unable to examine whether the associations we found with domains of cognition were consistent across different facets of gait or whether they varied with the condition under which the timed walk was undertaken. In one study, fastest walking speed was more strongly predictive of cognitive decline on the MMSE than usual walking speed (Deshpande et al. 2009). Thirdly, the tests of cognitive function used in ELSA were brief and may as a consequence be less reliable; this may have resulted in under-estimation of effect sizes. Fourthly, we treated all covariates as time-invariant; thus, we take account of the potential role that initial levels of these covariates might play in the longitudinal bidirectional associations between cognitive ability and walking speed, but we are not able to tell whether change in some of these covariates over the short follow-up period might play a part in these associations. Finally, in common with other longitudinal studies, especially in people of the age studied here, there was attrition over time and missing data on some covariates. In order to minimize the potential bias due to missing data, we used full information maximum likelihood estimation. Comparison of the proportions of the response levels within each covariate remained reasonably constant across waves. This suggests that it is reasonable to assume that data are missing at random and that no systematic bias has been introduced.

In this prospective study of men and women aged 60 to over 90 years, we found bidirectional associations between better performance on tests of different domains of fluid cognition and faster walking speed that were for the most part only partially explained by our covariates. There was some evidence that walking speed and the cognitive domains of executive function and processing speed may change in parallel with increasing 
age. As with previous investigations into this association based solely on older people, we were not able to ascertain whether change in walking speed precedes change in cognition or vice versa. Longitudinal data on cognition and walking speed from much earlier in life would give us a clearer understanding of the origins of this relationship and how it changes with age. It might also inform the development and timing of interventions.

Acknowledgments We are grateful to the UK Data Archive for supplying the ELSA data. The original data creators, depositors or copyright holders, the funders of the data collections and the UK Data Archive bear no responsibility for the analysis or interpretation presented here.

The Centre for Cognitive Ageing and Cognitive Epidemiology is funded by the Biotechnology Sciences Research Council, the Engineering and Physical Sciences Research Council, the Economic and Social Research Council, the Medical Research Council and the University of Edinburgh as part of the cross-council Lifelong Health and Wellbeing initiative (G0700704/84698). Catharine Gale, Avan Aihie Sayer and Cyrus Cooper are supported by the Medical Research Council (MRC_MC_UU_12011/2 and MRC_MC_UP_A620_1015).

Open Access This article is distributed under the terms of the Creative Commons Attribution License which permits any use, distribution, and reproduction in any medium, provided the original author(s) and the source are credited.

\section{References}

Alfaro-Acha A, Al Snih S, Raji MA, Markides KS, Ottenbacher $\mathrm{KJ}$ (2007) Does 8-foot walk time predict cognitive decline in older Mexicans Americans? J Am Geriatr Soc 55:245-251

Atkinson HH, Cesari M, Kritchevsky SB, Penninx BW, Fried LP, Guralnik JM, Williamson JD (2005) Predictors of combined cognitive and physical decline. J Am Geriatr Soc 53:11971202. doi:10.1111/j.1532-5415.2005.53362.x

Atkinson HH, Rapp SR, Williamson JD, Lovato J, Absher JR, Gass M, Henderson VW, Johnson KC, Kostis JB, Sink KM, Mouton CP, Ockene JK, Stefanick ML, Lane DS, Espeland MA (2010) The relationship between cognitive function and physical performance in older women: results from the Women's Health Initiative Memory Study. J Gerontol A Biol Sci Med Sci 65:300-306. doi:10.1093/gerona/glp149

Auyeung TW, Lee JSW, Kwok T, Woo J (2011) Physical frailty predicts future cognitive decline - a four-year prospective study in 2737 cognitively normal older adults. J Nutr Health Aging 15:690-694

Backman L, MacDonald SWS (2006) Death and cognitionsynthesis and outlook. Eur Psychol 11:224-235

Banks J, Karlsen S, Oldfield Z (2003) Socio-economic position. In: Marmot M, Banks J, Blundell R, Lessof C, Nazroo J (eds) Health, wealth and lifestyles of the older population in England. Institute of Fiscal Studies, London, pp 71-125
Bohannon RW (1997) Comfortable and maximum walking speed of adults aged 20-79 years: reference values and determinants. Age Ageing 26:15-19

Callisaya ML, Beare R, Phan TG, Blizzard L, Thrift AG, Chen J, Srikanth VK (2013) Brain structural change and gait decline: a longitudinal population-based study. J Am Geriatr Soc 61: 1074-1079. doi:10.1111/jgs.12331

Campisi J, d'Adda di Fagagna F (2007) Cellular senescence: when bad things happen to good cells. Nat Rev Mol Cell Biol 8: 729-740. doi:10.1038/nrm2233

Campisi J, Andersen JK, Kapahi P, Melov S (2011) Cellular senescence: a link between cancer and age-related degenerative disease? Semin Cancer Biol 21:354-359. doi:10.1016/j. semcancer.2011.09.001

Christensen H, Griffiths K, Mackinnon A, Jacomb P (1997) A quantitative review of cognitive deficits in depression and Alzheimer-type dementia. J Int Neuropsychol Soc 3:631-651

Clouston SA, Brewster P, Kuh D, Richards M, Cooper R, Hardy R, Rubin MS, Hofer SM (2013) The dynamic relationship between physical function and cognition in longitudinal aging cohorts. Epidemiol Rev. doi:10.1093/epirev/mxs004

Cooper R, Hardy R, Sayer AA, Ben-Shlomo Y, Birnie K, Cooper C, Craig L, Deary IJ, Demakakos P, Gallacher J, McNeill G, Martin RM, Starr JM, Steptoe A, Kuh D (2011) Age and gender differences in physical capability levels from mid-life onwards: the harmonisation and meta-analysis of data from eight UK cohort studies. Plos One 6:e27899. doi:10.1371/ journal.pone.0027899

Deary IJ, Johnson W, Gow AJ, Pattie A, Brett CE, Bates TC, Starr JM (2011) Losing one's grip: a bivariate growth curve model of grip strength and nonverbal reasoning from age 79 to 87 years in the Lothian Birth Cohort 1921. J Gerontol Ser B Psychol Sci Soc Sci 66:699-707. doi:10.1093/geronb/ gbr059

Debette S, Markus HS (2010) The clinical importance of white matter hyperintensities on brain magnetic resonance imaging: systematic review and meta-analysis. BMJ 341:c3666. doi: 10.1136/bmj.c3666

Demakakos P, Cooper R, Hamer M, de Oliveira C, Hardy R, Breeze E (2013) The bidirectional association between depressive symptoms and gait speed: evidence from the English Longitudinal Study of Ageing (ELSA). PLoS One 8:e68632. doi:10.1371/journal.pone.0068632

Deshpande N, Metter EJ, Bandinelli S, Guralnik J, Ferrucci L (2009) Gait speed under varied challenges and cognitive decline in older persons: a prospective study. Age Ageing 38:509-514. doi:10.1093/ageing/afp093

Dore GA, Elias MF, Robbins MA, Budge MM, Elias PK (2008) Relation between central adiposity and cognitive function in the Maine-Syracuse Study: attenuation by physical activity. Ann Behav Med 35:341-350. doi:10.1007/s12160-008-9038-7

Elias MF, Wolf PA, D'Agostino RB, Cobb J, White LR (1993) Untreated blood pressure level is inversely related to cognitive functioning: the Framingham Study. Am J Epidemiol 138:353-364

Guven C, Lee WS (2013) Height, aging and cognitive abilities across Europe. Econ Hum Biol. doi:10.1016/j.ehb.2013.12.005

Hardy R, Cooper R, Aihie Sayer A, Ben-Shlomo Y, Cooper C, Deary IJ, Demakakos P, Gallacher J, Martin RM, McNeill G, Starr JM, Steptoe A, Syddall H, Kuh D, HALCyon Study team (2013) Body mass index, muscle strength and physical performance in 
older adults from eight cohort studies: the HALCyon programme. PLoS One 8:e56483. doi:10.1371/journal.pone. 0056483

Himann JE, Cunningham DA, Rechnitzer PA, Paterson DH (1988) Age-related changes in speed of walking. Med Sci Sports Exerc 20:161-166

Holtzer R, Verghese J, Xue XN, Lipton RB (2006) Cognitive processes related to gait velocity: results from the Einstein aging study. Neuropsychology 20:215-223

Inzitari M, Newman AB, Yaffe K, Boudreau R, de Rekeneire N, Shorr R, Harris TB, Rosano C (2007) Gait speed predicts decline in attention and psychomotor speed in older adults: the health aging and body composition study. Neuroepidemiology 29:156-162

Jokinen H, Lipsanen J, Schmidt R, Fazekas F, Gouw AA, van der Flier WM, Barkhof F, Madureira S, Verdelho A, Ferro JM, Wallin A, Pantoni L, Inzitari D, Erkinjuntti T (2012) Brain atrophy accelerates cognitive decline in cerebral small vessel disease: the LADIS study. Neurology 78:1785-1792. doi:10. 1212/WNL.0b013e3182583070

Kenny RA, Coen RF, Frewen J, Donoghue OA, Cronin H, Savva GM (2013) Normative values of cognitive and physical function in older adults: findings from the Irish Longitudinal Study on Ageing. J Am Geriatr Soc 61(Suppl 2):S279-S290. doi:10.1111/jgs.12195

Killane I, Donoghue OA, Savva GM, Cronin H, Kenny RA, Reilly RB (2013) Variance between walking speed and neuropsychological test scores during three gait tasks across the irish longitudinal study on aging (TILDA) dataset. Conference proceedings: Annual International Conference of the IEEE Engineering in Medicine and Biology Society IEEE Engineering in Medicine and Biology Society Conference 2013:6921-6924. doi:10.1109/EMBC.2013.6611149

Koster A, Penninx BW, Bosma H, Kempen GI, Newman AB, Rubin SM, Satterfield S, Atkinson HH, Ayonayon HN, Rosano C, Yaffe K, Harris TB, Rooks RN, van Eijk JT, Kritchevsky SB (2005) Socioeconomic differences in cognitive decline and the role of biomedical factors. Ann Epidemiol 15:564-571

Kramer AF, Erickson KI, Colcombe SJ (2006) Exercise, cognition, and the aging brain. J Appl Physiol 101:1237-1242

Martin KL, Blizzard L, Wood AG, Srikanth V, Thomson R, Sanders LM, Callisaya ML (2013) Cognitive function, gait, and gait variability in older people: a population-based study. J Gerontol A Biol Sci Med Sci 68:726-732. doi:10.1093/ gerona/gls224

Nooyens AC, van Gelder BM, Verschuren WM (2008) Smoking and cognitive decline among middle-aged men and women: the Doetinchem Cohort Study. Am J Public Health 98:22442250. doi:10.2105/AJPH.2007.130294

Park DC, Reuter-Lorenz P (2009) The adaptive brain: aging and neurocognitive scaffolding. Ann Rev Psychol 60:173-196. doi:10.1146/annurev.psych.59.103006.093656

Rosano C, Simonsick EM, Harris TB, Kritchevsky SB, Brach J, Visser M, Yaffe K, Newman AB (2005) Association between physical and cognitive function in healthy elderly: the health, aging and body composition study. Neuroepidemiology 24 : $8-14$

Rosano C, Brach J, Longstreth WT Jr, Newman AB (2006) Quantitative measures of gait characteristics indicate prevalence of underlying subclinical structural brain abnormalities in high-functioning older adults. Neuroepidemiology 26:5260. doi: $10.1159 / 000089240$

Rosano C, Longstreth WT Jr, Boudreau R, Taylor CA, Du Y, Kuller LH, Newman AB (2011) High blood pressure accelerates gait slowing in well-functioning older adults over 18years of follow-up. J Am Geriatr Soc 59:390-397. doi:10. 1111/j.1532-5415.2010.03282.x

Schmidt R, Petrovic K, Ropele S, Enzinger C, Fazekas F (2007) Progression of leukoaraiosis and cognition. Stroke 38:26192625

Singh-Manoux A, Kivimaki M, Glymour MM, Elbaz A, Berr C, Ebmeier KP, Ferrie JE, Dugravot A (2012) Timing of onset of cognitive decline: results from Whitehall II prospective cohort study. BMJ 344. doi:10.1136/bmj.d7622

Soumare A, Tavernier B, Alperovitch A, Tzourio C, Elbaz A (2009) A cross-sectional and longitudinal study of the relationship between walking speed and cognitive function in community-dwelling elderly people. J Gerontol A Biol Sci Med Sci 64:1058-1065. doi:10.1093/gerona/glp077

Steffick DE, The HRS working group (2000) Documentation of affective functioning measures in the Health and Retirement Study. HRS/AHEAD Documentation Report DR-005 [online report]. http://hrsonline.isr.umich.edu/sitedocs/userg/dr-005. pdf. Accessed 18 May 2014

Steptoe A, Breeze E, Banks J, Nazroo J (2013) Cohort profile: the English Longitudinal Study of Ageing. Int J Epidemiol 42: 1640-1648. doi:10.1093/ije/dys168

Studenski S, Perera S, Patel K, Rosano C, Faulkner K, Inzitari M, Brach J, Chandler J, Cawthon P, Connor EB, Nevitt M, Visser M, Kritchevsky S, Badinelli S, Harris T, Newman AB, Cauley J, Ferrucci L, Guralnik J (2011) Gait speed and survival in older adults. JAMA 305:50-58. doi:10.1001/ jama.2010.1923

Tabbarah M, Crimmins EM, Seeman TE (2002) The relationship between cognitive and physical performance: MacArthur studies of successful aging. J Gerontol A Biol Sci Med Sci 57:M228-M235

Taylor R, Conway L, Calderwood L, Lessof C (2003) Methodology. In: Marmot M, Banks J, Blundell R, Lessof C, Nazroo J (eds) Health, wealth and lifestyles of the older population in England: the 2002 English Longitudinal Study of Ageing. Institute of Fiscal Studies, London, pp 357-374

Verghese J, Wang C, Lipton RB, Holtzer R, Xue X (2007) Quantitative gait dysfunction and risk of cognitive decline and dementia. J Neurol Neurosurg Psychiatry 78:929-935. doi:10.1136/jnnp.2006.106914

Verghese J, Mahoney J, Ambrose AF, Wang CL, Holtzer R (2010) Effect of cognitive remediation on gait in sedentary seniors. $\mathrm{J}$ Gerontol A Biol Sci Med Sci 65:1338-1343. doi:10.1093/ gerona/glq127

Waldstein SR, Snow J, Muldoon MF, Katzel LI (2001) Neuropsychological consequences of cardiovascular disease. In: Tarter RE, Butters M, Beers SR (eds) Medical neuropsychology, 2nd edn. Kluwer Academic/Plenum, New York

Watson NL, Rosano C, Boudreau RM, Simonsick EM, Ferrucci L, Sutton-Tyrrell K, Hardy SE, Atkinson HH, Yaffe K, Satterfield S, Harris TB, Newman AB (2010) Executive function, memory, and gait speed decline in wellfunctioning older adults. J Gerontol A Biol Sci Med Sci 65: 1093-1100. doi:10.1093/gerona/glq111 
White DK, Neogi T, Nevitt MC, Peloquin CE, Zhu YY, Boudreau RM, Cauley JA, Ferrucci L, Harris TB, Satterfield SM, Simonsick EM, Strotmeyer ES, Zhang YQ (2013) Trajectories of gait speed predict mortality in well-functioning older adults: the Health, Aging and Body Composition Study. J Gerontol A Biol Sci Med Sci 68:456-464. doi:10.1093/gerona/ gls197
Yogev-Seligmann G, Hausdorff JM, Giladi N (2008) The role of executive function and attention in gait. Mov Disord 23:329-342

Zaninotto P, Sacker A, Head J (2013) Relationship between wealth and age trajectories of walking speed among older adults: evidence from the English Longitudinal Study of Ageing. J Gerontol A Biol Sci Med Sci 68:1525-1531. doi:10.1093/gerona/glt058 